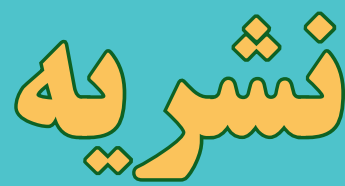
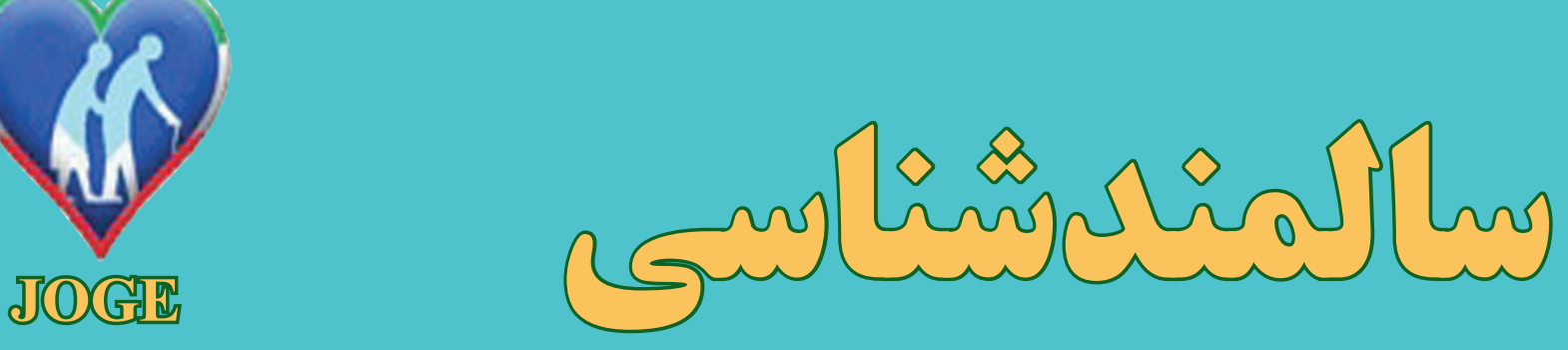

\section{دوره دوه شماره ا تابستان عqسا شماره استاندارد بين المللى I+FVY-VF}

1

برر سى ار تباط بين سبك هاى شوخ طبعى و حمايت اجتماعى با رضايت جنسى در زنان سالمند متأهل .

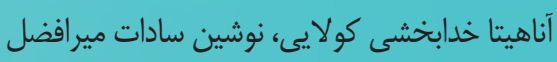

11 بر رسى اثر بخشى فعاليت بدنى بر ميزان سلامت عمومى، شادكامى و اميد بـ زندكى زنان سالمند و يائسه

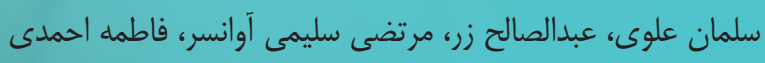

$r$ رابطه حمايت اجتماعى و كيفيت زندكى مرتبط با سلامت سالمندان شهر تبريز سال هو هارئ.

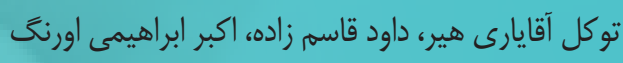

rq. تأثير فَّاليتهاى جسمانى بر كيفيت زندكَى، اميد و رضايت از زندَّى سالمندان شهر ايلام شمسالذين رضايى، محسن اسماعيلى

i) عوامل مرتبط با رفتار هاى خود مر اقبتى سالمندان مبتلا به فشارخون شهر اروميه بر اساس مدل اعتقاد بهداشتى . صابر يورمحمد، زهرا جليلى

Q) . حمايت درك شده عاطفى از ديدكاه سالمندان ايرانى: تحليل محتواى هدايت شده ...

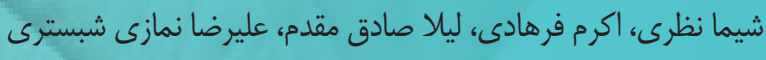

90. تأثير هشت هفته تمرين تركيبى بر ميزان تصفيدى كَلومرولى و آمادَّى جسمانى در مردان سالمند

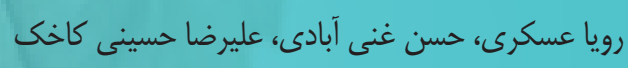

ve بر رسى نقش قدرت عضلانى و دامنه حر كتى اندام تحتانى در سقوط سالمندان: مطالعه مرورى نظام مند ... على باصغر نورسته، حامد زارعى، يدرام يور محموديان

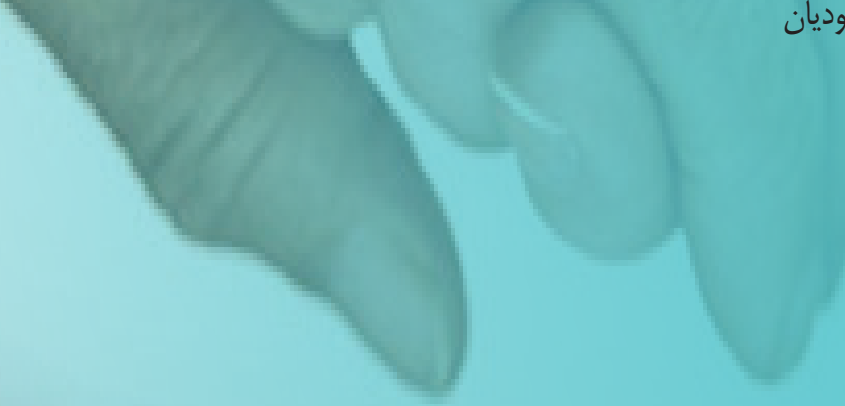




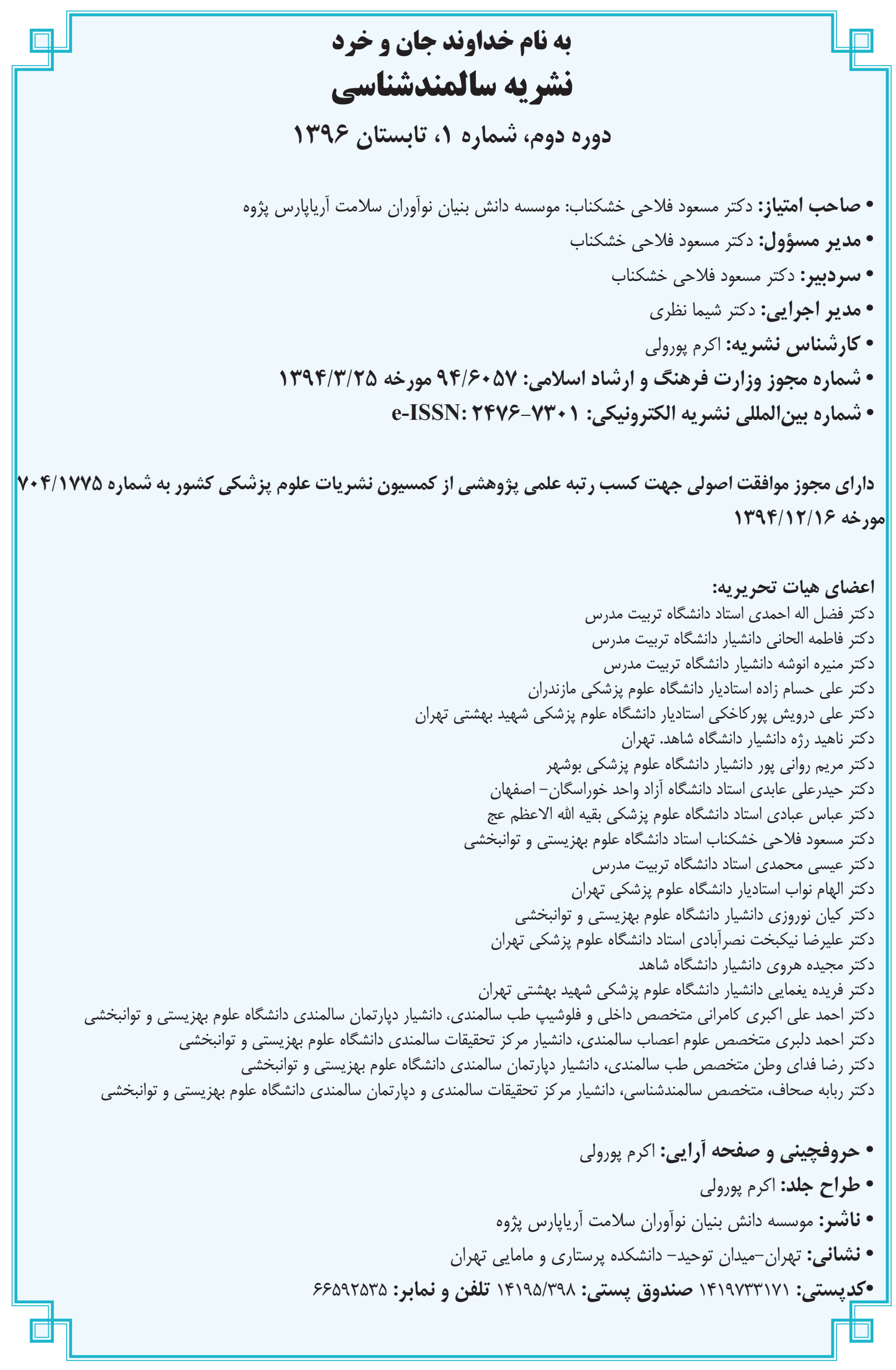


بررسى اثر بخشى فعاليت بدنى بر ميزان سلامت عمومى، شادكامى و اميد به زندكى زنان سالمند و يائسه

سلمان علوى'، *قعبدالصالح زرّ، مرتضى سليمى آوانسرّ، فاطمه احمدى؟

CrossMark

dick for updates

ا - كروه مديريت ورزشى، دانشكده علوم ورزشى، دانشخاه عالامه طباطبايى، تهران، ايران.

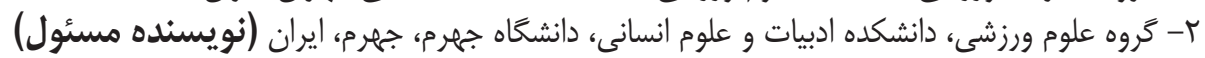
يست الكترونيكى: salehzar@gmail.com

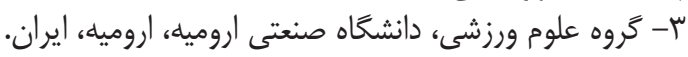

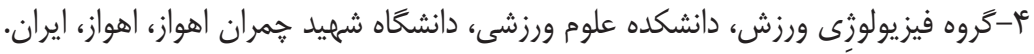

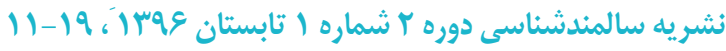

\section{جكيده}

مقدمه: يائسكى رخدادى طبيعى است كه در دوران ميانسالى اتفاق مى افتد كه در طولانى مدت اثرات منفى در فرد به جامى كذارد.

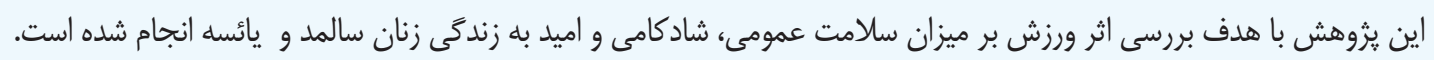

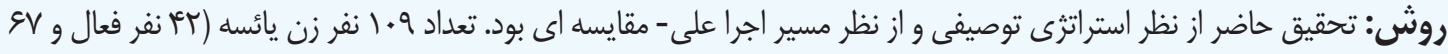

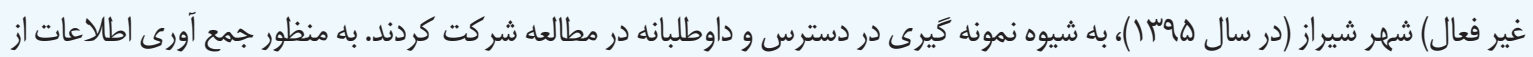

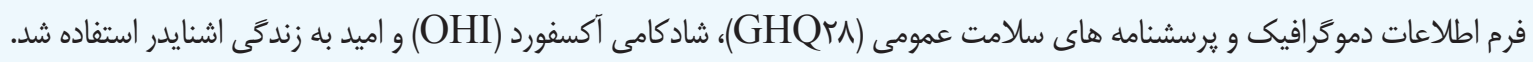

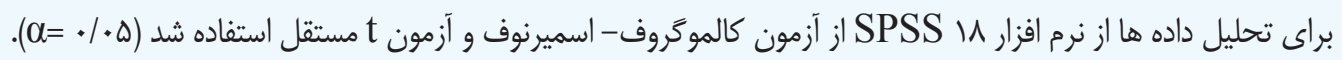

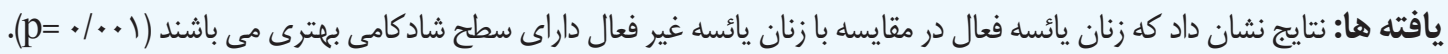

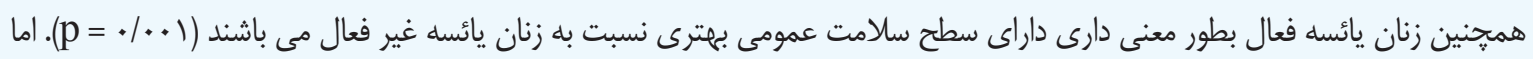

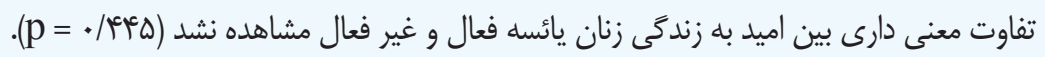
نتيجه كيرى: با توجه به يافته هاى تحقيق مى توان جنين كَفت كه انجام فعاليت بدنى و ورزش مى تواند بأند باعث بهببود سلامت

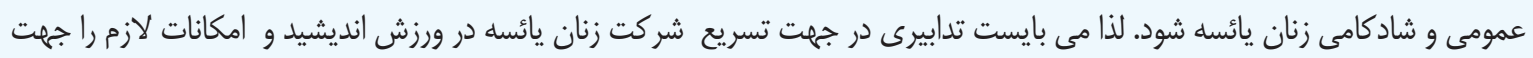
انجام فعاليت ورزشى در اختيار اين قشر قرار داد ماد.

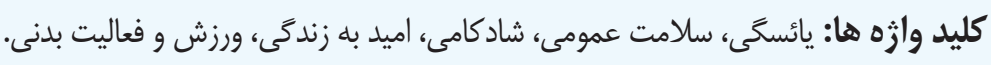
تاريخ بذيرش:|19/9

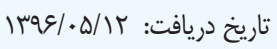

\begin{tabular}{|l|l|}
\hline \multicolumn{3}{|c|}{ Access this article online } \\
\hline
\end{tabular}


تاييد كرده اند (•(V). تحقيق شكوهى مقدم و همكارانش (•وس")

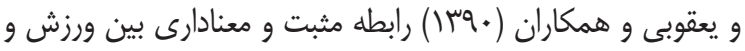

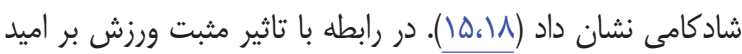

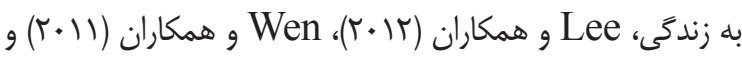
Keeler

با وجود اينكه ييشينه هاى ذكر شده نشان از سهم بزرك

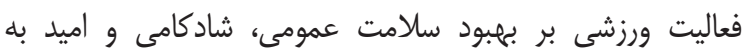
زندگى دارد، اما مطالعات اندكى بر روى ورزش به عنوان عاملى در جهت بهبود سلامت زنان يائسه صورت كرفته است. با توجه به ازدياد جمعيت زنان يائسه كه در دوران يائسكى با مشكلاتى باتى جون كَرَرفتخَى، تعريق شبانه، كاهش عملكرد شناختى و سر كيجها، بيمارى هاى قلبى_عروقى، اختالات خواب، سرطان، درد عضلانى، ترني،

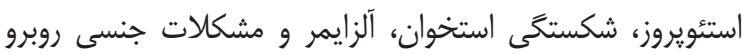

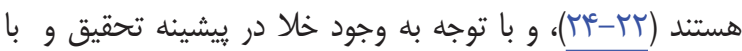
نظر به اينكه تقريبا يك سوم زندگى زنان، در مرحله يائسكى سيرى

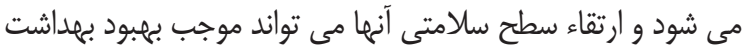
عمومى جامعه و بهداشت خانواده شود، سوال اصلى ما اين است كه آيا فعاليت بدنى و ورزش بر سلامت عمومى، شادكامى و اميد به زندگى زنان يائسه اثر مثبت مى كذارد؟

\section{ووش مطالعها}

تحقيق حاضر توصيفى و از نوع على - مقايسه اى مى باشد. جامعه يزوهش را زنان يائسه شهر شيراز تشكيل مى دهند. تعداد 9. نفر به روش نمونه گيرى دردسترس به عنوان نمونه آمارى، به طور

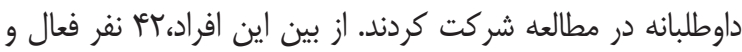

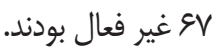

افرادى كه حداقل ب جلسه يك ساعته در هفته فعاليت بدنى داشتند در كروه فعال فعال و افرادى كه هيج كَونه فعاليت بدنى در هفته نداشتند در كروه غير فعال قرار كرفتند. ملاك ورود به مطالعه عبارت بودند از داشتن سن بالاى •ه سال، و حداقل \& ماه از تاريخ قطع قاعدكى آنها كذشته بود، و

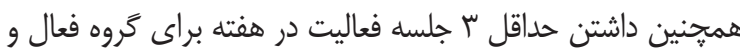
نداشتن هيج كَونه فعاليت بدنى براى كَروه غير فعال. سبِ محقق هدف از انجام مطالعه را براى آزمودنى ها تشرح

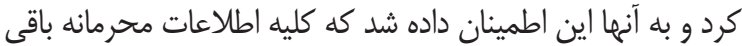
مى ماند و از اين اطلاعات صرفاً در اين مطالعه استفاده خواهد شد. همه افراد فرم رضايت آكاهانه جهت شركت در اين مطالعه راتكميل
مقامه

يكى از وقايع طبيعى زندگى زنان، يائسكى است اما برخى

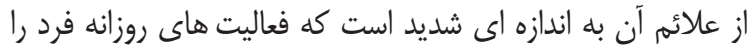

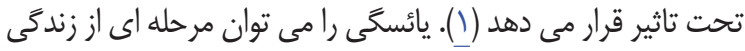
دانست كه با قطع دائمى قاعدىى همراه است كه دليل آن از دست آنس

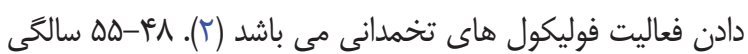
را سن شروع يائسگى مى دانند كه مى توان كفت با افزايش اميد به زندכى، حدود يك سوم زندگى زنان در اين مرحله سيرى مى شود

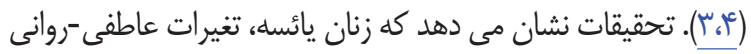
و متابوليكى متعددى را تجربه مى كنند كه اين تغييرات ، بررسى و برنامه ريزى در نظام سلامت زنان را مى طلبد (عه). اختالاتى

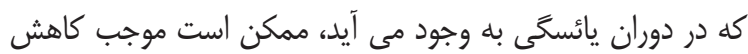
كيفيت زندگى، سلامت عمومى، شادكامى و اميد به زند بحى آنان شود (V.ᄉ) بدنى، روانى و اجتماعى و نه فقط نداشتن بيمارى و نقص عضو تعريف مى كند (9). سلامت انسان به عوامل بسيارى مانند؛ وراثت،

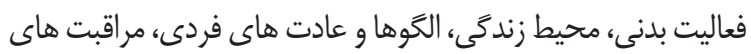
يزشكى و به طور كلى شيوه ز زندكى و ساير زمينه هاى خانوادگى،

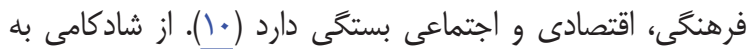

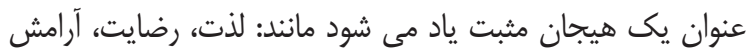

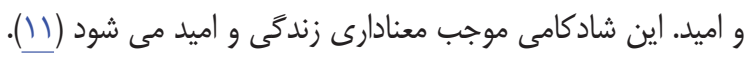
شادكامى مى تواند از افراد در برابر فشارهاى روانى محافظت كند و

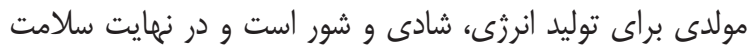

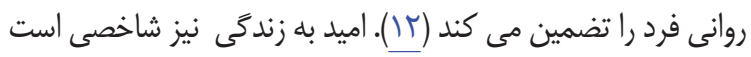

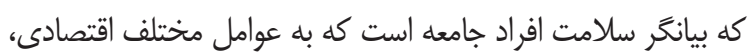

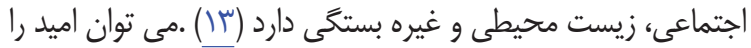

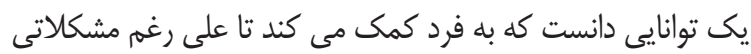

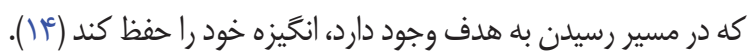

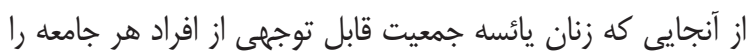
به خود اختصاص مى دهند، ضرورى مى شود تا اقداماتى در جهت

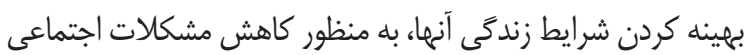

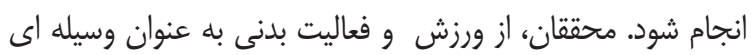
براى درمان مشكلات روانشناختى استفاده مى كنند و معتقدند كه به وسيله آن مى توان سلامت روانى و شادكامى و اميد به زندكى درى

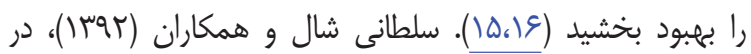
تحقيقى بر روى دانشجويان به اين نتيجه رسيدند كه ورزش موجب

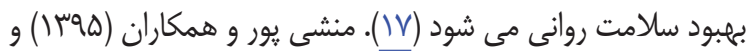

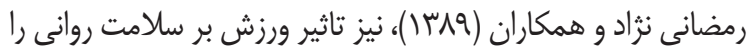




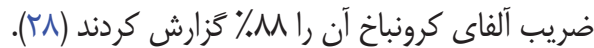
يرسشنامه اميد به زندگى اشنايدر: اين برسشنامه يك ابزار خودسنجى مى باشد كه از كا كَيه تشكيل شده است. از اين

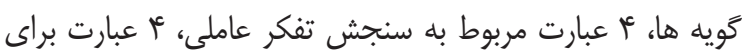

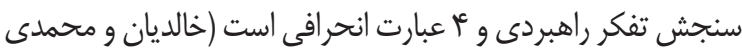
فر،اجوسا). شيوه نمره كذارى آن بر اساس طيف ليكرت ه كزينه

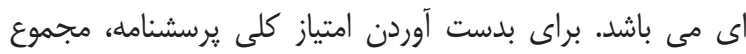

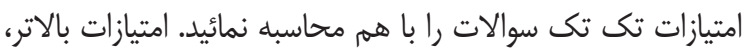
نشان دهنده اميد به زندگى بيشتر در فرد ياسخ دهنده خواهد بود و برعكس. در يثوهش خالديان و محمدى فر (أوسا)، ضريب اعتبار

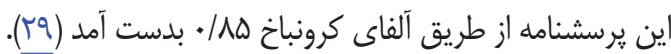

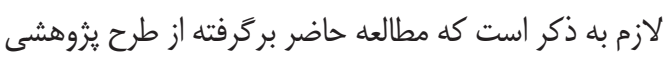

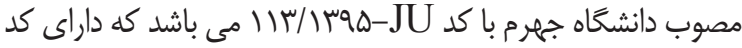

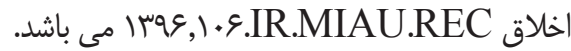

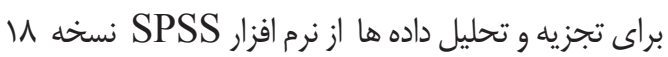
استفاده شد. تجزيه و تحليل داده ها از طريق آمار توصيفى (ميانكين

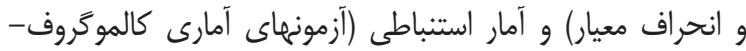
اسميرنوف و تى مستقل) انجام شد. سطح معنى دارى ه•|

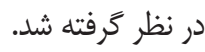

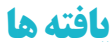

بررسى داده ها با آزمون كالموگروف- اسميرنوف نشان داد كه داده هاى تحقيق حاضر از توزيع طبيعى برخوردار هستند. ميانگين سن، قد و وزن زنان يائسه فعال و غير فعال در (جدول () نشان داده

شده است.
كردند. در نهايت افراد فرم اطلاعات شخصى و سه برسشنامه مورد نظر توسط آزمودنى ها تكميل شد. به منظور جمع آورى اطلاعات از يرسشنامه استفاده شد. به منظور سنجش سلامت عمومى از يرسشنامه سلامت روانى و سنجش شادكامى از طريق يرسشنامه شادكامى (GHQrA)

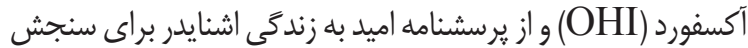
اميدوارى به زندگى استفاده شد. روايى صورى و محتوايى ابزارها توسط • ا تن از اساتيد مديريت ورزشى و فيزيولوزى ورزشى مورد

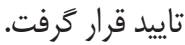

يرسشنامه سلامت عمومى (rA-GHQ): اين يرسشنامه

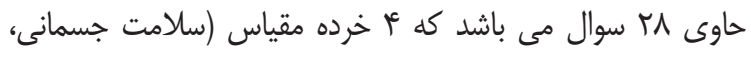
اضطراب و اختلال خواب، كاركرد اجتماعى و افسردگى) را مى سنجد. به منظور نمره دهى سلامت عمومى آزمودنى ها از مقياس أ ارزشى إخى

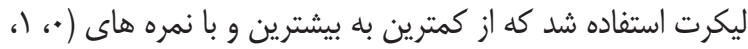

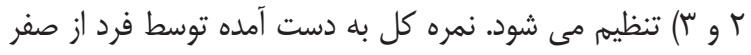

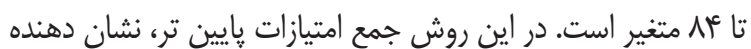

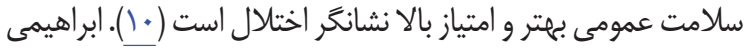

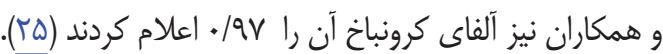
Oxford Happiness) يرسشنامه شادكامى آكسفورد Questionnaire OHQ تشكيل شده است كه نمره كذارى كزينه هاى هر عبارت به ترتيب آنسان

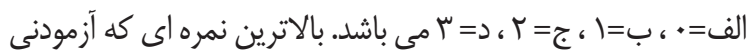

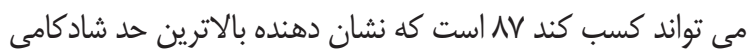
است و كمترين نمره اين يرسشنامه صفر است كه بيانكر شادكامى بايين و وجود افسردىى است (وَ، YV). باوى و خدابخشى كولايى

\begin{tabular}{|c|c|c|}
\hline غير فعال & فعال & متغير \\
\hline 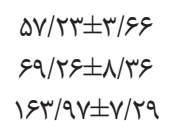 & $\begin{array}{l}\Delta V / \& q \pm \Delta / \wedge \digamma \\
q V / / F \pm V / \Delta V \\
\mid \xi \backslash / \& q \pm V / q \wedge\end{array}$ & 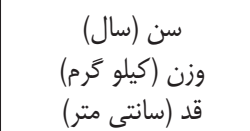 \\
\hline
\end{tabular}

عمومى زنان يائسه فعال و غيرفعال وجود دارد (1 +. / (p=). به طورى كه زنان يائسه فعال به طور معنى دارى داراى سطح سلامت عمومى بهترى نسبت به زنان يائسه غير فعال مى باشند. اما در مورد اميد به زندگى نتايج نشان داد كه تفاوت معنى دارى بين اميد به زندگى زنان

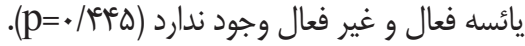

نتايج آزمون t مستقل در مورد نمره كلى شادكامى زنان

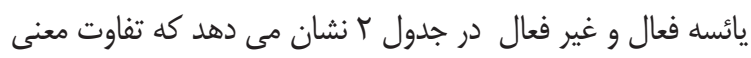
دارى بين سطح شادكامى زنان يائسه فعال و غير فعال وجود دارد

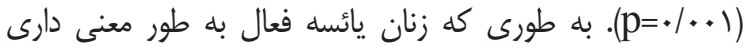
داراى سطح شادكامى بهترى نسبت به زنان يائسه غيرفعال مى بـ باشند. همجنين نتايج نشان داد تفاوت معنى دارى بين سطح سلامت 
جدول ب: نتايج آزمون t مستقل در مورد سطح شادكامى، اميد به زندگى و سلامت عمومى زنان يائسه فعال و غير فعال

\begin{tabular}{|c|c|c|c|}
\hline $\mathrm{p}$ & ميانگين و انحراف معيار & كروه & متغير \\
\hline$*+1 .+1$ & $\begin{array}{l}r N / \varepsilon| \pm| r / \cdot q \\
r \cdot / \cdot r \pm N / V r\end{array}$ & غير فعال & سطح شادكامى \\
\hline - AFD & $\begin{array}{l}r q / \mu \cdot \pm f / r q \\
r N / \Delta \cdot \pm \Delta / r q\end{array}$ & غير فعال & اميد به زندگى \\
\hline$* \cdot 1+.1$ & $\begin{array}{l}r \cdot / q T \pm V / \| Q \\
r g / F+ \pm I T / \kappa q\end{array}$ & غير فعال & سلامت عمومى \\
\hline
\end{tabular}

* : نشان تفاوت معنى دارى بين دو ميانكين

وسيله ورزش افزايش يافته و اشتغالات منفى از ذهن انسان دور مى

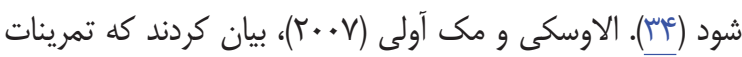

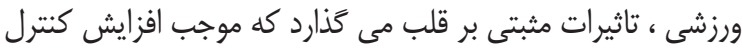
ياراسمياتيك قلب و كاهش كنترل سمياتيكى مى شود كه اين مسئله

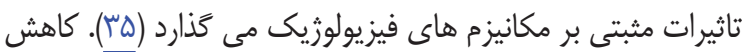

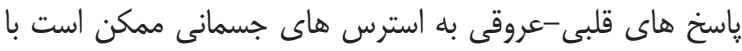
كاهش ياسخ به استرس هاى هيجانى -روانى همراه شود كه نتيجه

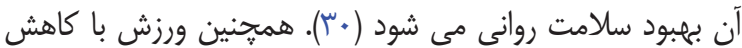

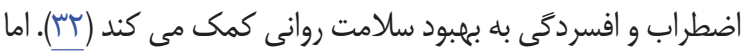
اين نتيجه تحقيق، با مطالعه عنبرى و همكاران (اج"آ) همخوانى

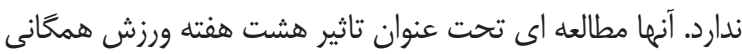
بر آمادىى جسمانى و سلامت عمومى كارمندان مرد انجام دادند؛ نتيجه تحقيق آنها رابطه معنى دارى بين ورزش و سلامت عمومى راني

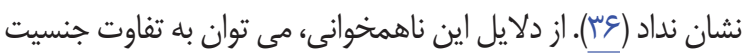

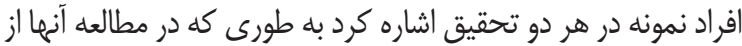
مردان كارمند استفاده شده است اما در اين مطالعه از زنان يائسه ؛ و و همجنين در مطالعه عنبرى و همكارانش، فقط اثر هشت هفته فعاليت ورزشى (به صورت مداخله ایى) بر سلامت عمومى مورد بررسى قرار

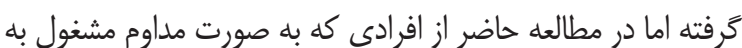

فعاليت ورزشى بودند، به عنوان نمونه استفاده شده است.

همجنين نتايج تحقيق نشان داد كه زنان يائسه فعال از ندان

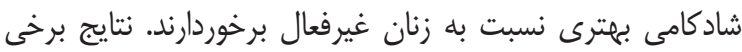

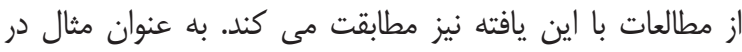

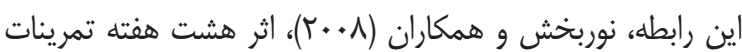
ايروبيك بر شادكامى زنان غير ورزشكار را مثبت و معنى دار اعلام إمار

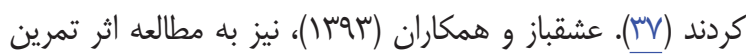
هوازى بر شادكامى زنان يرداختند، كه نتايج آنان با نتيجه تحقيق حاضر يكسان بود (يَّ). در تحقيقى ديخر صادقى و همكارارانش

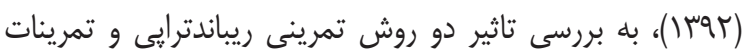
هوازى روى علائم بالينى و شادكامى افراد مبتلا به آسم يرداختند. نتايج أنها نشان داد كه هر دو روش تمرينى بر مئر ميزان شادكامى تاثير

\section{تحث}

بشر در طول زندگى خود از مراحل مختلفى عبور مى كند

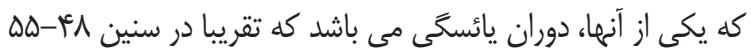
سالكى در زنان رخ مى دهد. در اين دوران سلامت عمومى و كيفيت إنى

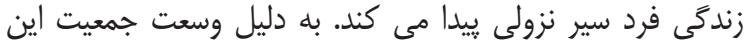

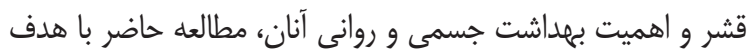
بررسى اثر فعاليت بدنى و ورزش بر سلامت عمومى، شادكامى و اميد

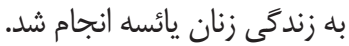
نتايج مطالعه حاكى از موثر بودن ورزش و فعاليت بدنى بر بان بهبود سلامت عمومى بود. بطورى كه زنان يائسه فعال بطور معنى

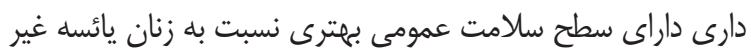
فعال مى باشند. نتايج برخى مطالعات همسو با اين يافته تحقيق مى الشى باشد. به عنوان مثال كاشفى و همكاران (بوسا)، در مطالعه خود

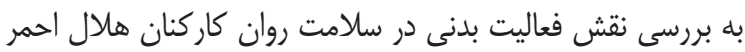

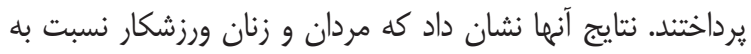

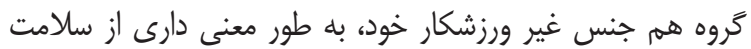

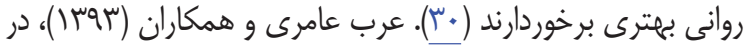

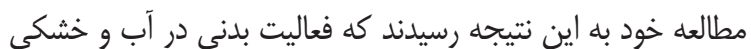
بر سلامت عمومى زنان سالمند اثر مثبت مى كذارد (آّ) در تحقيقى

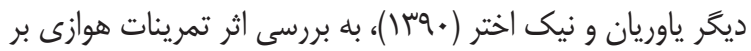

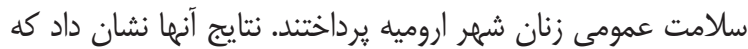

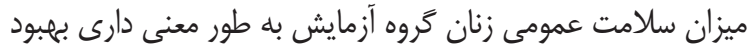

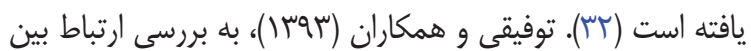
ميزان فعاليت بدنى با سلامت عمومى در دانشجويان يرداختند كه

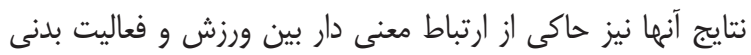

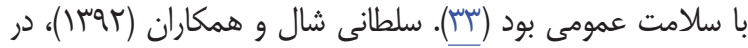
مطالعه اي به بررسى اثربخشى ورزش بر سلامت عمومى، كيفيت

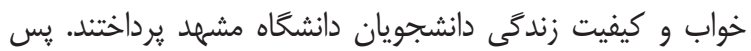

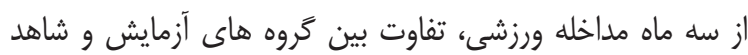

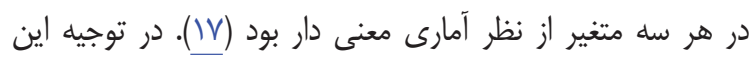
نتيجه بدست آمده مى توان بيان كرد كه تعاملات اجتماعى به آله 
به كاركرد ضد افسردگى ورزش، كه مى توان آن را مهمترين عامل

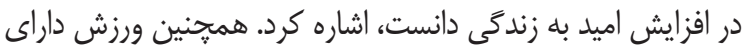
قابليتهاى تفريحى، درمانى و رقابتى است كه مى تواند كمك شايانى به توسعه و حفظ عملكرد جسمانى و روانى، افزايش رضايت از زندكى دئى و بهبود كيفيت زندَّى بكند (9).

\section{نتيجه تيرى نهائى}

به طور كلى نتايج نشان داد كه ورزش و فعاليت بدنى موجب ارتقاء ميانكين سلامت عمومى، شادكامى و اميد به زندگى زنان يائسه مى شود. با توجه به ازدياد جمعيت زنان يائسه ضرورى مى شود كه

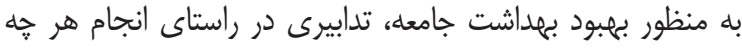

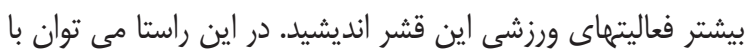
اطلاع رسانى به وسيله رسانه هاى كروهى و بركزارى همايش هايى فيى إنى با موضوع ورزش و تندرستى، آكاهى آنان را نسبت به مزاياى ورزش،

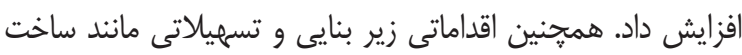
فضاهاى ورزشى مخصوص سالمندان (بخصوص زنان)، ساخت جاده

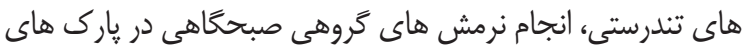

$$
\text { عمومى، ييشنهاد مى شود. }
$$

ابزار اندازه گيرى، سن آزمودنى ها و ميزان سواد تحصيلى آنها

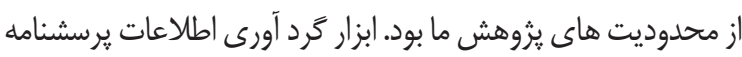
بود كه با توجه به سن بالاى آزمودنى ها كه معمولا در اين سنين افر اد بى حوصله و داراى درك پإيين تر مى باشند، ممكن است آنها

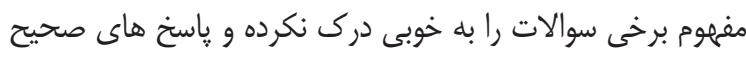

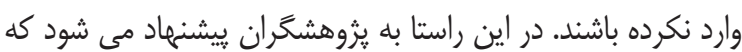
در مطالعات خود، در كنار ابزار يرسشنامه، از مصاحبه و مشاهده نيز استفاده كنند. برخى از آزمودنى ها داراى سواد آكادميك يايين بودند

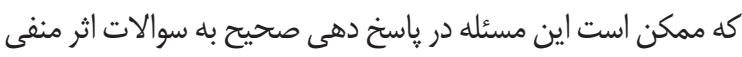
كذاشته باشد. مى توان در مطالعات آينده كه بر روى افراد سنين بالا صورت مى گيرد، در كنار آزمودنى، از يكى از اعضاى خانواده او نيز

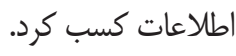

تعارض منافع: ."هيج كَونه تعارض منافع توسط نويسندكان

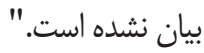

\section{تشكر و قدر فانى - مانى}

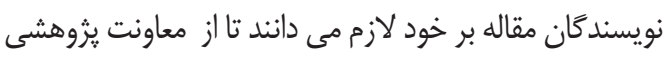
دانشخاه جهرم و همجنين تمامى آزمودنى هايى كه در انجام اين

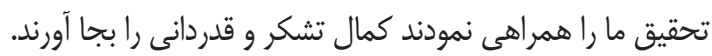

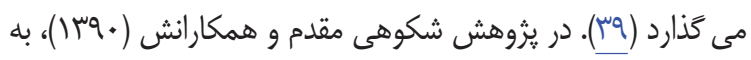
بررسى اثر ورزش بر سلامت روانى و شادكامى دانش آموزان مقطع متوسطه يرداخته شد كه نتايج آنها نيز با اين يافته تحقيق، همسو مئى

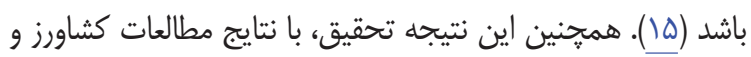

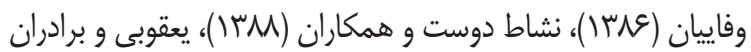

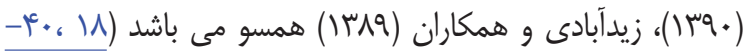

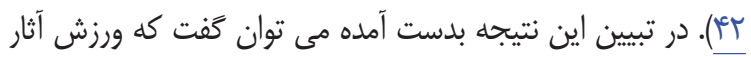

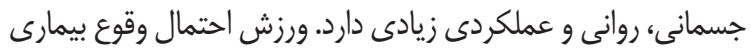
هايى خون حملات قلبى، خطر سرطان، فشار خون، خاقى، ديابت، يوكى استخان و كمر درد را كاهش مى دهد و همجنين إنين موجب بهبود عملكرد دستخاه كوارش و اصلاح خواب مى شود كه نتيجه

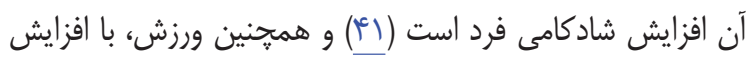

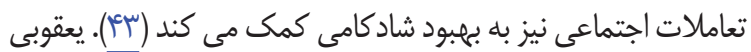

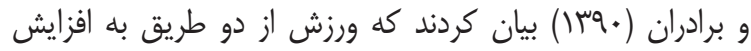
شادكامى فرد كمى مى كند؛ الف) رها كردن آندورفين ها (ايجاد كننده احساسات خوشايند)، ب) كاهش سطح كورتيزول (هورمونى كه با فشار عصبى در خون ترشح مى شود (1). در بايان مى توان

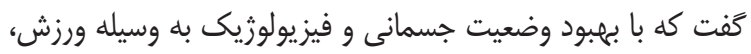
فرد در انجام امور خود موفق تر عمل مى كند كه به اين امر موجب اعتماد به نفس بيشتر و در نتيجه احساس خرسندى و شادكامى

بيشتر مى شود (q"). آخرين يافته تحقيق نشان داد كه تفاوت معنى دارى بين اميد

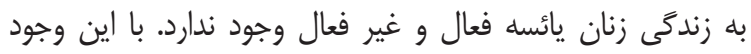

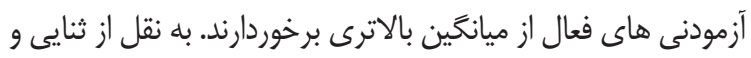

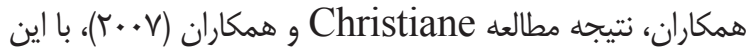
يافته همخوانى دارد. به عبارتى ديخر آنها نيز رابطه معنادارى بين

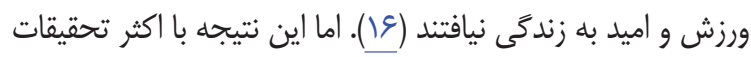

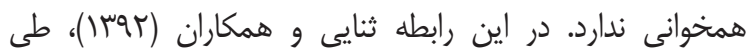
تحقيقى، به بررسى اثر فعاليت بدنى بر كيفيت زندگى و اميد به زندكى النى

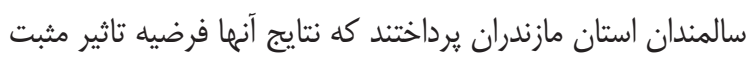

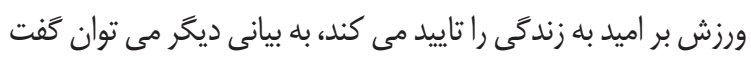

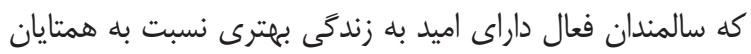

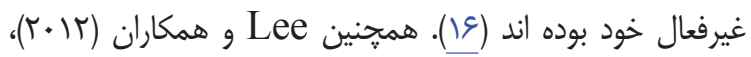

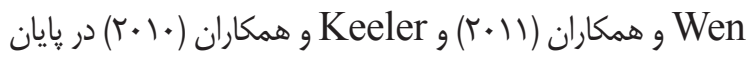
مطالعات خود كزارش كردند كه فعاليت ورزشى بر افزايش اميد به

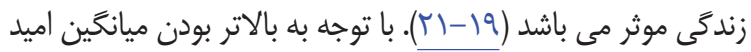

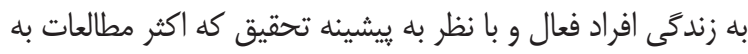
اثربخشى ورزش بر ميزان اميد به زندكى تاكيد كرده اند، مى تولى توان 


\section{References}

1. Makvandi S, Zargar Shushtari S, Yazdizadeh H, Zaker Hoseini V, Bastami A. Frequency and Severity of Menopausal Symptoms and Its Relationship with Demographic Factors in Pre-and Postmenopausal Women of Ahvaz, Iran. Journal of Obstetrics, Gynecology and Infertility. 2013;16 (49.50):7-15.

2. Jalili L, Yazdi Zadeh $H$, Sharifi N, Abedi P, Najar S, Asad Mobini E. The Relationship between Physical Activity and the Severity of Menopause Symptoms in Menopausal Women in Ahvaz. Journal of Obstetrics, Gynecology and Infertility. 2014; 17 (2):15-23.

3. Fritz MA, Speroff L. Clinical gynecologic endocrinology and infertility. 8thed. philadelphia: Lippincott Williams \& Wilkins2011. 643-57 p.

4. Golyan Tehrani S, Ghobadzadeh M, Arastou M. Promoting Health Status of Menopausal Women by Educating Self Care Strategies. . Hayat. 2007;13 (3):6775.

5. Afghari A, Ganji J, Ahmad Shirvani M. Psycho-Emotional Changes in Menopause: A Qualitative Study. J Mazandaran Univ Med Sci. 2012; 22 (93):27-38.

6. Farahmand M, Ramazani Tehrani F, Momenan AA, GHanbarian A, Azizi F. Comparison of metabolic changes after natural menopause and surgical menopause. Journal of payesh. 2013; 12 (6):637-47.

7. Monshipour SM, Mokhtari Lakeh N, Rafat F, Kazemnejad Leili E. Related factors to Menopausal women's quality of life in Rasht . Holist Nurs Midwifery. 2016; 26 (1): 80-8.

8. Cahoon C. Depression in older adults. The American journal of nursing. 2012;
112 (11): 22-30.

9. Alavi S, Ahmadi MA, Zar A. Evaluate the Effectiveness of Sport on Job Burnout, General Health and Life Expectancy in Jahrom University of Medical Sciences Staff. Community Health. 201;4(3):1609.

10. ramazani negad $R$, Niazi $M$, Hemati nezhad M. comparing general health between participated people in sport activity and inactive people quarterly . journal of sport sciences. 2010;2(4):4966.

11. Abedi A, Hevrat A. Comparing the effectiveness of Fordyce's cognitivebehavioral approach and social skills training approach on increasing High school students' happiness in Isfahan, Iran, Proceedings of the 3rd International Conference of Teaching and Learning. International University, Malaysia. 2011: 59-71.

12. Pelechano V, Gonzalez-Leandro $\mathrm{P}$, Garcia L, Moran C. Is it possible to be too happy? Happiness, personality, and psychopathology. Inter J Clin Heal Psycho. 2013; 13 (1):18-24.

13. panahi $H, A l$ Imran $A$. The effect of inflation, Health expenditure and Urbanization The life expectancy In Countries Middle East and North Africa. Journal of payesh. 2016; 15 (4): 345-50.

14. Mehrinejad A, Rajabi Moqaddam S. Evaluating the Effectiveness of Logo Therapy in Increasing Hope to Life in Addicts with Short-Term Addiction Recovery. journal of Clinical Psychology Studies. 2012; 2 (8): 29-42.

15. SHokohi Moghadam S, Zivari Rahman M, lesani M. The Role of Sport at Mental Health and Happiness in High School Students in Kerman. Journal of Health \& psychology. 2012; 1 (3): 61-80. 
16. Sanaei M, Zardoshtian SH, Norouzi R. The effect of physical activity On quality of life and life expectancy In the elderly Fars province. . journal of sport management studies. 2014; 5 (17):13757.

17. Soltani Shal R, Aghamohammadian Sharbaf H, Ghanaei chamanabad A. Effect of exercise on general health, quality of sleep and quality of life in Ferdowsi University of Mashhad students. Journal of Qazvin University of Medical Sciences 2013; 17 (4): 39-46.

18. Yagoobi H, Baradaran M. Correlates Of Mental Health: Happiness Sport, Emotional Intelligence. Journal of Modern psychological Reserches. 2011; 6 (23): 201-21.

19. Keeler E, Guralnik JM, Tian H, Wallace $\mathrm{RB}$, Reuben DB. The impact of functional status on life expectancy in older persons. The Journals of Gerontology Series A: Biological Sciences and Medical Sciences. 2010; 65 (7):727-33.

20. Lee I-M, Shiroma EJ, Lobelo F, Puska P, Blair SN, Katzmarzyk PT, et al. Effect of physical inactivity on major noncommunicable diseases worldwide: an analysis of burden of disease and life expectancy. The lancet. 2012; 380 (9838): 219-29.

21. Wen CP, Wai JPM, Tsai MK, Yang YC, Cheng TYD, Lee M-C, et al. Minimum amount of physical activity for reduced mortality and extended life expectancy: a prospective cohort study. The Lancet. 2011;378 (9798):1244-53.

22. Bahri N, Afiat M, Aghamohamadian HR, Delshad Noughabi A, Bahri N. Investigating the Relationship between Severity of Menopausal Symptoms and Depression, Anxiety and Other Menopausal Symptoms. Journal of
Obstetrics Gynecology and Infertility. 2013;16 (43):14-20.

23. Faraji R, Asgharnia M, Hosseinzadeh F, Dalil heirati SF, Emadi A. Attitude and knowledge of women about menopause and hormone replacement therapy. Holist Nurs Midwifery. 2014; 24 (1):48-55.

24. SHifren J1, Schiff I. Menopause.In: Berek JS, Berek DL. Berek and Novak's gynecology. 15thed. Philadelphia: Lippincott Williams \& wilkins. 2012: 1233-48.

25. Ebrahimi A, Molavi H, Moosavi G, Bornamanesh A, Yaghobi M. Psychometric Properties and Factor Structure of General Health Questionnaire 28 (GHQ-28) in Iranian Psychiatric Patients. Journal Reserch Behavior Sciences. 2007; 5 (1):5-12.

26. Fouladchang M, Hassannia S. The Effectiveness of Emotional Regulation on Happiness and Self -Efficacy of Female- Headed Households. Journal of Voman \& Society. 2015; 5 (20): 89-106.

27. Farokhi E, Sabzi N. happiness and perception of family communication pattern:the mediating role of psychological capital. Journal of Developmental psychology: Iranian Psychologists. 2015; 11 (43): 313-24.

28. Bawi L, KHodabakhshi Koolaee A. Comparison of Mental Health, Happiness, and Emotion Control. With Adolescents Residential centers of state welfare organization and family Reared Adolescents. Community Health. 2015; 2 (3):157-64.

29. Khaledian M, Mohammadifar MA. On the Effectiveness of Group CognitiveBehavioral Therapy and Logotherapy in Reducing Depression and Increasing Life Expectancy in Drug Addicts. Research On Addiction. 2016; 9 (36): 63-80. 
30. Kashefi M, Arab Ameri E, Houmanian D. The relationship between exercise and gender in mental health of staff of Red Crescent society of Tehran. Journal of Rescue \& Relief. 2014; 5 (4).

31. Arabameri E, Taheri M, Irani K. The effect of water-based exercise programs and KSD protocol on general health questionnaire and optimal physical fitness factors affecting female elders balance. Journal of Motor Behavior. 2014; 6 (16):15-28.

32. Yavarian Y, Nikakhtar M. Effects Of Aerobic Exercise, On Women Mental Health. J Urmia Nurs Midwifery Fac. 2011; 9 (1):0-.

33. Tofighi A, Babaei S, Eloon Kashkuli F, Babaei R. The Relationship Between The Amount Of Physical Activity And General Health In Urmia Medical University Students. J Urmia Nurs Midwifery Fac. 2014; 12 (3): 166-72.

34. Schmitz Z, Kruse K, Kugler J. he association. The association between physical exercises and health-related quality of life in subjects with mental disorders: results from a cross-sectional survey. T Prey Med 2004; 39 (6):120-7.

35. Elavsky S, MC Auley E. Lack of perceived sleep improvement affer 4 month structured exercise prograns. . Menopause. 2007;14 (3.1): 535-40.

36. Anbari SH, Moghadasi M, Torkfar A, Rahimezadeh E, Khademi Y. The Effects of the Recommended Eight-weeks sports-for-all Program on Physical Fitness and General Health of Male Employees. . Armaghane danesh,. 2012; 17 (1): 40-9.

37. Norbakhsh M, Alijani E, Rismanbaf Z. The Effect of Eight weeks Aerobic Exercise on Self-efficacy and Happiness of non-athlete Female. Journal of physical education and sport scince. 2008; 2 (4): 37-48.

38. Eshghbaz M, Arefi M, Nouri g. The effect of aerobic training on happiness, social communication skills and life satisfaction in women. journal of Woman and Family Studies. 2014; 7 (25):69-92.

39. Sadeghi M, Ghasemi G, Miralaei A. The effects of rebound therapy and aerobic training on clinical symptoms and happiness, in asthmatic patients. Journal of Research in sport Rehabilitation. 2014; 1 (2):19-25.

40. Keshavarz A, Vafaeian M. Study of influential factors on the amount of happiness. Journal of Appplied Psychology. 2008; 2 (5).

41. Neshat Doost H, Kalantari M, Mehrabi $\mathrm{H}$, Palahang H, Nouri NS. Predicting Factors of Happiness in Mobarekeh Steal. jas. 2009; 20 (1):105-18.

42. Zeydabadi R, Ranjbar R, Farokhi A, Zare Zarchi M, Mehdizadeh R. The Study of Longitudinal on changes aerobic fitness level and happiness physical education students. Journal of sport management and action behavior. 2010; 6 (11): 25-40.

43. Argyle M. The Psychology of Happiness. Routledge. 2013. 


\title{
Evaluate the Effectiveness of Physical Activity on General Health, Happiness and Life Expectancy in Postmenopausal and Elder Women
}

\author{
Alavai $\mathrm{S}^{1}$, *Zar A.S , Salimi Avansar $\mathrm{M}^{3}$, Ahmadi F ${ }^{4}$
}

1- Department of Sport Management, School of Sport Science, Allameh Tabtabaee University, Tehran, Iran.

2- Department of Sport Science, School of Literature and Humanities, Jahrom University, Jahrom, Iran. (Corresponding Author)

E-mail: salehzar@gmail.com

3-Department of Sport Sciences, Urmia University of Technology, Urmia, Iran.

4-Department of Exercise Physiology, School of Sport Science, Shahid Chamran University of Ahvaz, Ahvaz, Iran.

\section{Abstract}

Introduction: Menopause is a natural event that occurs in adulthood that in the long term can negative effects on the people. The aim of this study was to investigate the effect of exercise on general health, happiness and life expectancy in post-menopausal and elder women.

Method: The present research in terms of strategy is descriptive and it was comparative in terms of performance. A total of 109 postmenopausal women (42 active and 67 inactive) in Shiraz (in 1395) By Available sampling method and voluntarily to participated in the study.In order to collect information, we used of the demographic information form, General Health Questionnaire (GHQ28), Oxford Welfare (OHI) and Schneider Life expectancy. To analyze the data we used of SPSS/18, Kolmogorov-Smirnov test and independent t-test $(\alpha=0.05)$.

Results: The results showed that active postmenopausal women compared to inactive postmenopausal women are better in happiness $(\mathrm{p}=0.001)$. And also active postmenopausal women significantly better in Public health than inactive postmenopausal women $(p=0.001)$. But there was no significant difference in the scale of the life expectancy between two group $(\mathrm{p}=0.445)$.

Conclusion: According to the research findings, it can be said that Physical activity and exercise can improve overall health and happiness in postmenopausal women. Therefore, It must be resolved consider to accelerate postmenopausal women's participation in sports and provide the necessary facilities to exercise for this population.

Keywords: Menopause, general health, happiness, life expectancy, exercise and physical activity.

Received: 03/08/2017

Accepted: 10/09/2017

\begin{tabular}{|l|l|}
\hline \multicolumn{3}{|c|}{ Access this article online } \\
\hline & Website: \\
Www.joge.ir
\end{tabular}




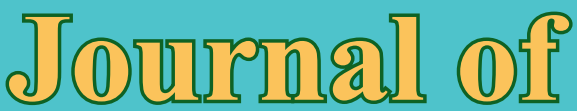

JOGG

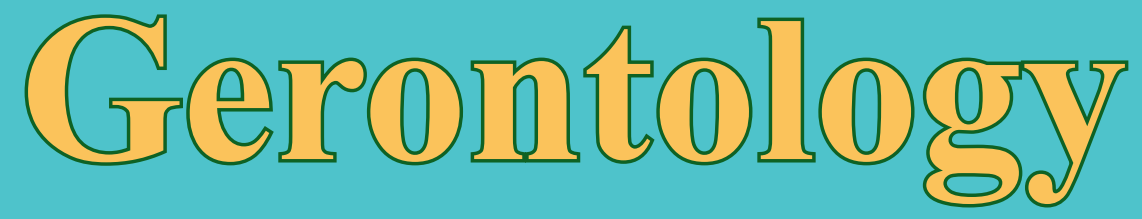

\section{Vol.2 No.1 Summer 2017 - ISSN: 2476-7301}

Relationship between Humor and Social Support with Sex Satisfaction in Elderly Married Women ... 10 Khodabakhshi-Koolaee A, MirAfzal NS

Evaluate the Effectiveness of Physical Activity on General Health, Happiness and Life Expectancy in Postmenopausal and Elder Women 19

Alavai S, Zar A.S, Salimi Avansar M, Ahmadi F

A study of relationship between social support and health-related quality of life among elderly people in Tabriz

Aghayari hir T, Ghasemzadeh D, Ebrahimi Orang A

The effect of physical activities on the quality of life, hope and life satisfaction among the elderly in Ilam city 40

Rezaei Sh, Esmaeili M

Related factors to self-care behaviors in elderly with hypertension based on the Health Belief Model in Uremia County 50

Poormuhamad S, Jalili Z

Perceived affective support From the Iranian older adult's viewpoint: a directed content analysis ...... 64 Nazari Sh, Farhadi A, Sadeghmoghadam L, Namazi Shabestari A.R

The effect of 8 weeks combined training on the physical fitness and rate of renal filtration in elderly men 75

Askari R, Ghani Abadi H, Hosseini Kakhki SA

Investigating the role of muscle strength and range of motion lower extremity in the elderly: A systematic review study 89

Norasteh A.A, Zarei H, Pour Mahmoodian P 